\title{
Pandemic and the City: A Melbourne Perspective for Community Resilience
}

\author{
Mark Allan
}

\begin{abstract}
Melbourne, Australia's most liveable city, has endured the nation's most severe lockdown measures as it plans for revitalisation. This chapter provides a snapshot of trends affecting generalised measures of liveability prior to and during COVID-19, and beyond. Collaboration between authorities and citizens is required for resilience and on-going adaptation.
\end{abstract}

\subsection{Introduction}

The coronavirus COVID-19 pandemic is a global crisis, it has taken lives and impacted the economies of developed and developing nations. Its impact on cities, in particular, has been unprecedented, requiring us to rethink ideas about sustainable built environments, urban proximity, density, and mobility. This paper presents some observations about Melbourne, a city with an enviable reputation for liveability and its response to COVID-19 and a future of co-existence with the pandemic.

Soon after the World Health Organisation's declaration of the COVID-19 pandemic in mid-March 2020, the Australian government implemented a program of financial support combined with travel restrictions, social distancing and other 'lockdown' measures. These restrictions generated considerable economic uncertainty and social anxiety in towns and cities across the country affecting households, government, and industry. By the end of June 2020 Australia's lockdown measures were showing comparative signs of success with some 7,008 people having recovered from the 7,767 reported cases of COVID-19 [1]. At about this time with states and territories reporting no new cases or small numbers restrictions began to be eased. In Melbourne, however, a second wave of COVID-19 emerged in July 2020 likely from a failure to adhere to hotel quarantine protocols. Community transmission of infection saw new daily case numbers rise from 15 to 20 in mid-June to over 600 by early August [2]. This led to stronger Stage 4 restrictions being introduced across metropolitan Melbourne for a six-week period on 2 August 2020, later extended. Server restrictions were also placed on movements between across state borders. During Stage 4 a curfew was put in place between the hours of $8 \mathrm{pm}$ and $5 \mathrm{am}$ requiring people to stay at home during these hours unless for work, medical care and caregiving. Face coverings were mandated when leaving home which was only allowed for permitted work, or to either exercise for up to one hour per day or for a sole member of each household to shop for food or essential items within a 5 kilometre radius of home. On 6 September 2020 'Victoria's Coronavirus (COVID-19) Roadmap to Reopening' was announced by the state's Premier. The 'Roadmap' sets out a four-step process to ease restrictions across Victoria staging expanded social interaction, and phasing in a return to 
the workplace, education, sport, recreation, ceremonies, and special occasions. The 'first step' is scheduled to commence on 13 September 2020 with the 'last step' targeting 'COVID Normal' after 23 November 2020 subject to 'trigger points and public health advice'.

\subsection{Growth of Inner-City Melbourne}

Melbourne is a global and liveable city known for its multicultural diversity and its cosmopolitan inner urban core. Recognised by the Economist Intelligence Unit as 'the world's most liveable city' for seven consecutive years (2010-17) and currently ranked number two, it has a legacy of leading international liveability rankings [3]. Melbourne's inner-city communities' express cultural diversity and creativity, home to major universities, hospitals, parks and gardens. The city hosts the nation's major sporting and entertainment events and its vibrant laneways and café culture draw international tourists and visitors. Melbourne is Australia's fastest growing city and its inner area is the nation's most densely populated area with 21,900 people per $\mathrm{km}^{2}$. In 2018-19 Melbourne's population grew by $2.3 \%$ to 5 million people fuelled by net overseas migration it was forecast to grow to 7 million by 2030 outstripping Sydney as Australia's largest city [4]. The ABS forecast net overseas migration to Melbourne will fall by $85 \%$ over the next 12 months.

\subsection{Reshaping Cities}

As we look to Melbourne for some contemporary lessons of resilience it is worth remembering that epidemic diseases have plagued, shaped and reshaped cities for millennia. The City of London responding to the great plague of 1665 enacted municipal orders quarantining 'infected houses' mandating inspections, requiring extra cleaning of housing and streets, restricting assemblies at theatres, and implementing trade embargos [5]. Responses to a succession of epidemics has profoundly shaped cities, housing forms, human behaviours, communications, and urban living environments. The reality of co-existing with COVID-19 and a succession of future pandemics will challenge how we plan, design and manage people-centric cities, public spaces and spatial connections in the context of epidemiological measures to control the spread of infectious diseases.

\subsection{Melbourne's Response to COVID-19}

The lockdown measures introduced in response to the first and second waves of COVID-19 in March and July 2020 have severely impacted inner Melbourne's visitor economy, international education, and the services economy. Melbourne's population increase was immediately halted and the number of weekly payroll jobs in central Melbourne significantly reduced. The million daily visitors to Melbourne's Central Business District (CBD) reduced more than $30 \%$ as international students and professional service workers stayed home and retail premises and hospitality venues closed. Weekday road traffic levels across Melbourne were down and pedestrian movements around train stations in central Melbourne were down by up to $42 \%$ in July [6]. The Melbourne City Council reported the average number of pedestrians in Bourke Street mall dropped from an average of 25,000 to 6,476 per day with an estimated 1 in 3 shops closed or vacant. Vacancy rates for CBD offices typically at $5 \%$ rose sharply to $7.6 \%$ in March, with real estate agents reporting student accommodation occupancy-rate falls in inner Melbourne of between 20\% and 50\% [7]. The immediate response gave priority to health and wellbeing, emergency accommodation was provided to the homeless and city 
cleaning regimes increased. In addition to financial loans and grants to small business, economic stimulus projects are planned to include infrastructure, housing and construction and affordable housing. Inner Melbourne fast tracked approvals for $12 \mathrm{~km}$ of temporary cycling lanes and has committed to plant 150,000 trees, shrubs and grasses (an increase from the 3,000 planned) [8]. The importance of high-quality public realm and open spaces for people to safely exercise and enjoy fresh air has been underscored during the pandemic.

\subsection{Impacts of COVID-19 on Central Melbourne's Liveability}

The observations presented in Table 42.1 are grouped into categories using headings form the seven targets in the United Nations Sustainable Development Goal Number 11 (SDG 11) for 'Sustainable Cities and Communities'. The SDGs comprise 17 global goals with interrelated targets and indicators aimed at delivering globally sustainable development by 2030 [9]. Table 42.1 presents a 'snapshot' of trends affecting generalised measures of Inner Melbourne's liveability immediately prior to COVID-19, during and potential future responses. Movements are summarized by symbols, upward and downward 'arrows' or a neutral 'square' with traffic light colours green, red or amber indicating positive, negative or neutral impacts on liveability.

\subsection{Planning to Co-Exist With COVID-19}

The trends summarised in Table 42.1 reflect optimism in the people of Melbourne's resilience and capacity to respond to both the current and the future impacts of the COVID-19 health and economic crisis. Reduced housing demand will place negative downward pressure on property prices, however, this will ease rental costs and increase affordability in some locations. While intimate partner violence and social isolation has generated social hardship during the pandemic increased mainstream media attention has helped raise public awareness and prioritised the importance of good mental health and public policy. A reduction in traffic congestion is expected to continue with less commuting by those with the flexibility to work from home. Fewer public transport trips, capacity constraints and increased cleanliness will necessitate revised pricing, implementation of new technologies and changed operations likely to reduce future investment. The design and management of buildings and public spaces will see a greater emphasis on human health and wellbeing. Spaces will need to be adaptable and able to accommodate physical distancing as demand for flexible outdoor spaces increases. Digital communications will play a larger role in connecting people and maintaining social ties.

The short-term halt in Melbourne's rapid population growth in the view of Professor Giles-Corti of RMIT University provides an opportunity for the state's planners to recalibrate how Melbourne grows and to better integrate urban development and infrastructure provision for a more sustainable city [10]. This may also assist planners to implement urban policies embracing of 'local liveability' including '20-minute neighbourhood'. This concept prioritises local transport and jobs with high quality public realm connecting services so that people's daily needs are met within a 20-minute walk from their home [11].

The built environment has a key role in developing the health and wellbeing of communities and responding to impacts of climate change. During the COVID-19 pandemic communities in cities like Melbourne have rapidly embraced working from home, video conferencing for education and tele-medicine and increased online shopping. Rethinking our cities as healthy places will likely increase the cleanliness of public transport and change the way we move about the city and interact socially in terms of proximity and density. Delivery of urban strategies to reallocate road space to create wider footpaths and more bicycle lanes combined with increased tree planting and public 
space and other investments in the public realm offers real potential to improve the mental, physical and immunological health of communities.

TABLE 42.1

Inner Melbourne Liveability, Trends in Response to COVD-19

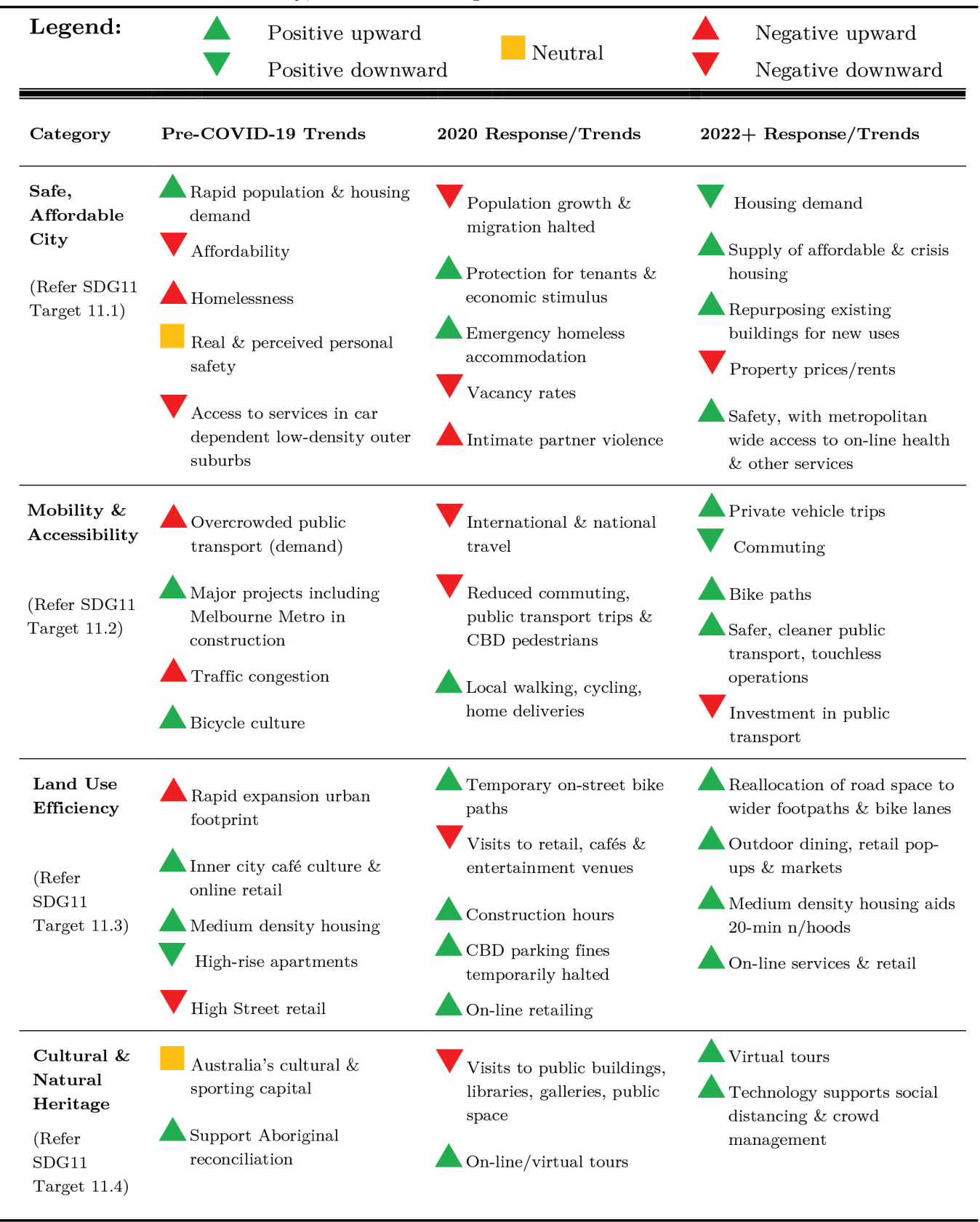


TABLE 42.1

Continued - Inner Melbourne Liveability, Trends in Response to COVD-19

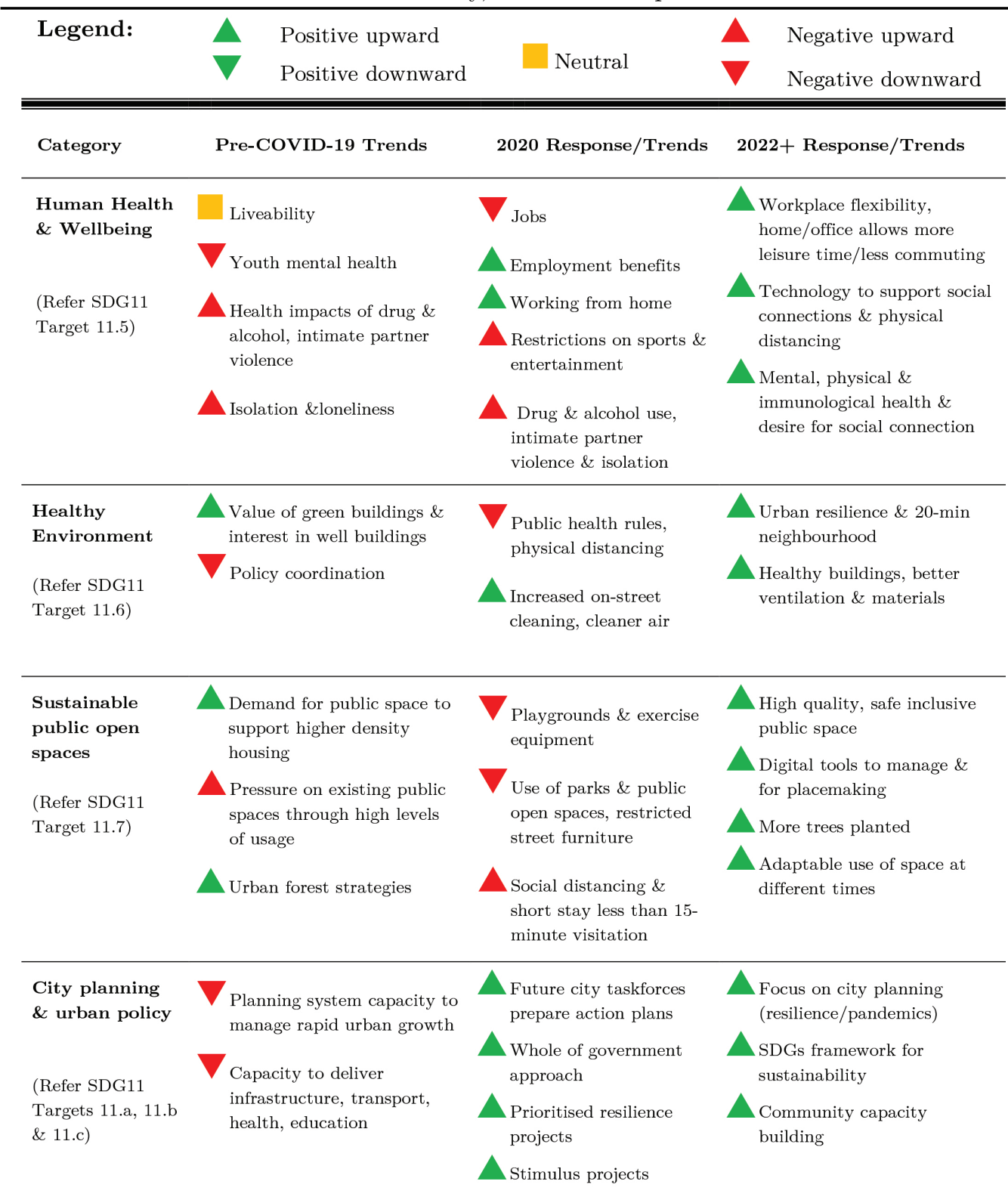

Melbourne has experienced significant downturns in its visitor economy, international education sector and its services economy due to the pandemic, exacerbated by Victoria's second wave of COVID-19 and hard lockdown measures introduced in August 2020. The economic adversity forecast, and currently affecting Australia has hit hardest in Victoria and most severely in the state's capital city. Since mid-March 2020 when the pandemic emerged in Australia until late August 2020 payroll jobs fell 4.2 per cent nationally, in Victoria this figure was 7.9 per cent [12] resulting in significant hardship for many households. To date Victoria's response to COVID-19 has been based on health advice and statistical modelling adopting a policy of aggressive suppression to avoid restrictions being continuously lifted and reinstated.

The conditional phased easing of restrictions outlined in Victoria's 'Roadmap to Reopening', 
September 2020, outlines public policy settings that balance human health priorities with the staged reopening of the state's economy. In addition to financial support for business and individuals, approvals for construction projects and delivery of national and state government services have been fast-tracked. Underpinning business and streamlining service delivery has also occurred at a local government level including plans for localised urban interventions and public realm improvements to revitalise city centres. In Melbourne streets, footpaths and parking bays are being converted for use as outdoor dining areas seating patrons at a safe distance as part of a staged return of people and strategies to revitalise the city.

Valuable lessons have had to been learnt quickly about how to plan, organise, and administer our city and safeguard citizens during a global pandemic. This awareness is important now and in the future as policies and action plans are developed to promote urban resilience to protect and improve human health and well-being. With Victoria now in economic recession, the outcomes of the serve lockdown will test the resilience and liveability of Melbourne as its capital. Just as Melbourne has responded to crises and economic downturns in the past, its social and physical infrastructure combined with the patience, optimism and creativity of its citizens, means it is well placed for a future that accepts and embraces reactivation and on-going adaptation.

\section{References}

[1] Australian Bureau of Statistics. 4940.0 - Household Impacts of COVID-19 Survey, 24-29 June $2020,2020$. URL https://www.abs.gov.au/ausstats/abs@.nsf/mf/4940.0. Retrieved July 20, 2020.

[2] Department of Health Victoria State Government and Human Services. Victorian coronavirus (COVID-19) data, 2020. URL https://www.dhhs.vic.gov.au/victorian-coronavirus-covid-19-data. Retrieved September 8,2020 .

[3] The Economist Intelligence Unit. Global Liveability Ranking. The Economist, 2020. URL https://www.eiu. com/topic/liveability. Retrieved July 20, 2020.

[4] Australian Bureau of Statistics. 3218.0 - Regional Population Growth, Australia, 2018-19, 2018. URL https: //www.abs.gov.au/AUSSTATS/abs@.nsf/mf/3218.0. Retrieved July 20, 2020.

[5] Lukas Engelmann, John Henderson, and Christos Lynteris. Plague and the City. Taylor and Francis, 2018.

[6] Ashleigh McMillian. Pedestrians Clear out of CBD in Droves after Second Lockdown. The Age, 2020. URL https://bit.1y/3jW3DEo. Retrieved July 20, 2020.

[7] Max Opray. How Covid-19 will change cities. The Saturday Paper, 2020. URL https://bit.ly/3bEs8TV. Retrieved July 20, 2020.

[8] C40 Cities Climate Leadership Group. C40: Agenda for a Green and Just Recovery. 2020. URL https: //www.c40.org/other/agenda-for-a-green-and-just-recovery. Retrieved July 20, 2020.

[9] United Nations. Habitat III Issue Papers 11 - Public Space, 2015.

[10] Jemimah Clegg. Melbourne's Slowing Population Growth Could Give Us Our Last Chance for Real Liveability. Domain, 2020. URL https://bit.1y/2GKE3Eh.

[11] Rory Shannon, James Mant, Marcus Dessewffy, and L Harrison. 20-minute neighbourhoods: Creating a more liveable melbourne. Journal of Transportation and Health, 14:100773, 2019.

[12] Australian Bureau of Statistics. Weekly Payroll Jobs and Wages in Australia, Week Ending 22 August 2020 2020. URL https://bit.1y/35jNLHS. Retrieved September 8, 2020. 